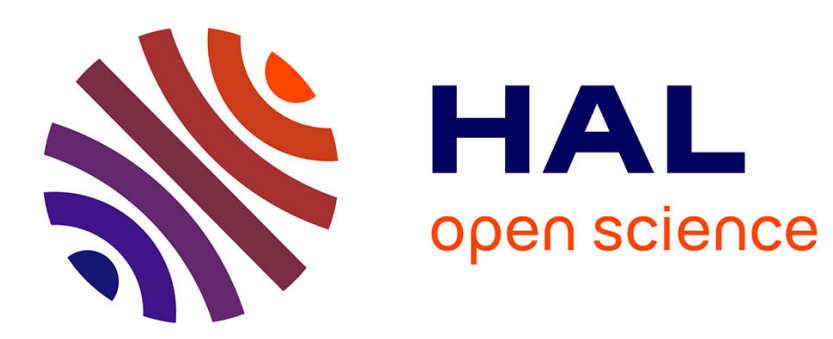

\title{
Possible neural mediation of the central effects of oxytocin on uterine motility
}

\author{
Anissa Benoussaidh, Yves Maurin, Olivier Rampin
}

\section{To cite this version:}

Anissa Benoussaidh, Yves Maurin, Olivier Rampin. Possible neural mediation of the central effects of oxytocin on uterine motility. AJP - Regulatory, Integrative and Comparative Physiology, 2005, 289, pp.R798-R804. hal-02670349

\section{HAL Id: hal-02670349 \\ https://hal.inrae.fr/hal-02670349}

Submitted on 31 May 2020

HAL is a multi-disciplinary open access archive for the deposit and dissemination of scientific research documents, whether they are published or not. The documents may come from teaching and research institutions in France or abroad, or from public or private research centers.
L'archive ouverte pluridisciplinaire HAL, est destinée au dépôt et à la diffusion de documents scientifiques de niveau recherche, publiés ou non, émanant des établissements d'enseignement et de recherche français ou étrangers, des laboratoires publics ou privés. 


\title{
Possible neural mediation of the central effects of oxytocin
}

\section{on uterine motility}

\author{
Anissa Benoussaidh, Yves Maurin, and Olivier Rampin \\ Analyse et Modélisation en Imagerie Biologique, NOPA-UR-Institut \\ National de la Recherche Agronomique 1197, Jouy-en-Josas, France
}

Submitted 3 February 2005; accepted in final form 19 April 2005

\begin{abstract}
Benoussaidh, Anissa, Yves Maurin, and Olivier Rampin. Possible neural mediation of the central effects of oxytocin on uterine motility. Am J Physiol Regul Integr Comp Physiol 289: R798-R804, 2005; doi:10.1152/ajpregu.00065.2005.-The central nervous system contains the nuclei at the origin of autonomic and neuroendocrine pathways to the uterus. Although the anatomical basis of these pathways is known, the conditions of their recruitment and their interactions in the context of copulation remain to be explored. We tested the hypothesis that some central mechanisms could simultaneously recruit both pathways to the uterus. In this aim, we recorded intrauterine pressure changes in anesthetized female rats at the estrus stage after intracerebroventricular (ICV) administration of oxytocin (OT). Doses of 0.3-300 ng elicited increases of frequency and amplitude of uterine contractions. These effects were partly mimicked by the OT agonist $\left[\mathrm{Thr}^{4}, \mathrm{Gly}^{7}\right] \mathrm{OT}$ but not by arginine vasopressin. They were blocked by the OT receptor antagonist atosiban delivered either ICV or intravenously. The latter suggests that ICV OT activated the systemic release of OT. The effects of OT were also blocked by hexamethonium, a ganglionic blocking agent, by atropine, a muscarinic receptor antagonist, and by $N^{\omega}$-nitro-L-arginine methyl ester, an inhibitor of nitric oxide synthesis. The results reveal that ICV OT recruits autonomic efferent pathways to the uterus. These results support our hypothesis that the activation of central nuclei can promote uterine contractility, and that OT may be a central coordinator of autonomic and neuroendocrine pathways. The hypothalamus, the source of direct OT-ergic projections to the pituitary, the brain stem, and the spinal cord, may be a target of central OT.
\end{abstract}

genital reflex; hypothalamic paraventricular nucleus; autonomic nervous system

UTERINE MOTILITY IS CONTROLLED by sex steroid hormones, by peptidergic hormones such as oxytocin (OT), by some local factors such as prostaglandins and nitric oxide (NO), and by neurotransmitters released by the autonomic nervous system (20). Therefore, the central nervous system controls uterine motility through a variety of pathways. A simple, direct, and well-recognized control is exerted by OT released from the terminals of magnocellular neurons into the bloodstream (40, 44). From there, OT reaches the uterus and interacts with OT receptors to contract uterine smooth muscle fibers (45-47). The uterus also receives an important autonomic innervation. The motor limb of this innervation originates in the dorsal motor nucleus of the vagus (cervical parasympathetic nucleus) $(13,30)$, in the intermediolateral column of the thoracolumbar spinal cord (sympathetic nucleus), and in the sacral parasympathetic nucleus (50). These motor autonomic nuclei receive

Address for reprint requests and other correspondence: O. Rampin, Analyse \& Modélisation en Imagerie Biologique, NOPA-UR-INRA 1197 Bât 325, Institut National de la Recherche Agronomique, 78352 Jouy-en-Josas Cedex, France (e-mail: olivier.rampin@jouy.inra.fr). information from the periphery as well as from supraspinal structures $(9,35)$. Among the latter is the paraventricular nucleus, which sends OT fibers to the spinal cord $(10,38,49)$. It is noteworthy that OT affects uterine motility when it is administered intrathecally both at the thoracolumbar and at the lumbosacral levels of the spinal cord (8).

Preganglionic neurons of the motor autonomic nuclei establish synaptic contacts with postganglionic neurons in a variety of pre- and paravertebral autonomic ganglia, including the paracervical ganglion (33). Ganglionic synapses are nicotinic cholinergic and blocked by hexamethonium.

The parasympathetic cholinergic pathway plays an important role in the control of uterine motility $(21,42,43)$. Parasympathetic postganglionic neurons synthesize and release not only acetylcholine $(34,48)$, whose stimulatory effects on the uterus are blocked by atropine, but also several other neuromediators such as NO (32), the synthesis of which is blocked by $N^{\omega}$-nitro-L-arginine methyl ester (L-NAME). Nitrergic transmission also affects uterine motility (16). Therefore, a series of pharmacological experiments have revealed the peripheral autonomic control of the uterus.

By contrast, data on the activation of motor autonomic nuclei are lacking. As mentioned above, the central nervous system may use one of several strategies to control uterine motility: activation of the neuroendocrine release of OT and/or activation of autonomic pathways.

The first aim of our study was to search for a central supraspinal mechanism controlling uterine motility. We have taken advantage of the observation that exogenous OT stimulates a positive feedback mechanism of OT release by the neurons of the paraventricular nucleus of the hypothalamus (28) to use intracerebroventricular (ICV) application of OT as a means of stimulating paraventricular neurons. The second aim of our study was to search for the pathways recruited by these mechanisms. To address these questions, we recorded intrauterine pressure (IUP) changes on ICV administration of OT to female rats at the estrous stage. This stage was selected for two reasons: 1) female rats are proceptive and fertilized during estrus (6), and 2) OT administered intrathecally exerts its greatest effects on uterine motility at the estrous stage (8). Arginine vasopressin (AVP) is a neuropeptide (the structure of which is close to that of OT) synthesized in the same brain nuclei as OT and identified as a partial OT receptor agonist (for review, see Ref. 5). On the other hand, OT binds the AVP receptor (5). [ $\left.\mathrm{Thr}^{4}, \mathrm{Gly}^{7}\right] \mathrm{OT}$ is a specific agonist of OT receptors, exhibiting a higher affinity for them than OT itself, and

The costs of publication of this article were defrayed in part by the payment of page charges. The article must therefore be hereby marked "advertisement" in accordance with 18 U.S.C. Section 1734 solely to indicate this fact. 
which does not bind the AVP receptor (15). We have tried to assess the role of central OT receptors in uterine motility by comparing the effects of ICV administration of OT or $\left[\mathrm{Thr}^{4}, \mathrm{Gly}^{7}\right] \mathrm{OT}$ or AVP.

\section{MATERIALS AND METHODS}

Animals. Adult female Sprague-Dawley rats weighing 250-300 g were purchased from René Janvier (Le Genest-St-Isle, France). Rats were housed in plastic cages containing wood-chip bedding. They had free access to commercial pelleted rodent chow (Scientific Animal Food \& Engineering, Augy, France) and tap water. Cages were placed in an animal facility maintained at $21^{\circ} \mathrm{C}$ and kept in a $12: 12-\mathrm{h}$ light-dark cycle (lights on at 8:00 AM). Experiments were performed in accordance with the European Economical Community Directive of November 24, $1986(86 / 609 / \mathrm{EEC})$ on the use of laboratory animals and with the National Research Council (NRC) publication Guide for Care and Use of Laboratory Animals (copyright 1996, National Academy of Science); the protocol was approved by the Local Ethics Committee (Agreement 04-003). All efforts were made to minimize animal suffering and to reduce the number of animals used. Estrus stage was identified by histological examination of daily vaginal smears according to the description by Long and Evans (26). After vaginal smears had indicated that regular 4-day cycles were present for at least two consecutive cycles, the animals were subjected to the experimental procedure.

Experimental procedures. Rats were anesthetized with an intraperitoneal injection of urethane $(1.2 \mathrm{~g} / \mathrm{kg}$ in sterile water $)$, and their temperature was maintained at $37^{\circ} \mathrm{C}$ using a homeothermic blanket.

To perform ICV catheterization, the rat head was fixed in a stereotaxic device (David Kopf, Tujunga, CA). Rats were implanted with a cannula directed toward the left lateral ventricle [coordinates: $1 \mathrm{~mm}$ anterior to bregma, $1.5 \mathrm{~mm}$ lateral to bregma, and $3.5 \mathrm{~mm}$ ventral to dura, according to Paxinos and Watson (36)]. The cannula was connected through a polyethylene tubing (PE-10) to a $25-\mu 1$ Hamilton syringe filled with artificial cerebrospinal fluid (aCSF) (in mM: $148 \mathrm{NaCl}, 3 \mathrm{KCl}, 1.4 \mathrm{CaCl}_{2} \cdot 2 \mathrm{H}_{2} \mathrm{O}, 0.8 \mathrm{MgCl}_{2} \cdot 6 \mathrm{H}_{2} \mathrm{O}, 0.8$ $\mathrm{Na}_{2} \mathrm{HPO}_{4}$, and $0.2 \mathrm{NaH}_{2} \mathrm{PO}_{4}$ ).

The jugular vein was catheterized with a polyethylene tubing (PE-10) filled with $\mathrm{NaCl}(0.9 \%)$ and connected to a Hamilton syringe also filled with $\mathrm{NaCl}(0.9 \%)$. Rats were tracheotomized to facilitate spontaneous breathing.

After an incision of the skin on the flank muscle was made, the left uterine horn was exposed. A small latex balloon (9 mm long, Balt Extrusion, Montmorency, France), attached to a $1.5 \mathrm{~mm}$-diameter catheter, was inserted into the lumen of the uterus through a small incision and pushed caudally close to the cervix. The balloon and the catheter were filled with sterile water and connected to a pressure transducer (Elcomatic 750, Phymep, Paris, France) to monitor the IUP. Pressure of the balloon was increased to record a basal pressure level between 0 and $10 \mathrm{mmHg}$. Pressure signal was amplified (Bionic Instruments, Phymep, Paris, France), sent to an analog-to-digital interface, sampled at a frequency of $5 \mathrm{~Hz}$, and stored in a personal computer until we performed off-line analyses using Axotape software (Axon Instruments, Union City, CA).

An experiment, carried out on one rat, consisted of ICV administration of $10 \mu \mathrm{l}$ of aCSF followed by successive administrations of $0.3,3,30$, and $300 \mathrm{ng}$ of either OT or AVP or $\left[\mathrm{Thr}^{4}, \mathrm{Gly}^{7}\right] \mathrm{OT}$ suspended in a volume of $10 \mu \mathrm{l}$. Each administration (including the initial aCSF injection) lasted for $20 \mathrm{~s}$ and was followed by a flush of $10 \mu \mathrm{l}$ of aCSF. Successive administrations were separated by a period of $15 \mathrm{~min}$. In experiments with atosiban, hexamethonium, atropine, or L-NAME, a single administration of either one of these compounds was performed before the first administration of aCSF. Table 1 displays the different experimental groups used in the present study.

At the end of the experiments, $10 \mu \mathrm{l}$ of pontamine skye blue were injected ICV, followed by a flush of $10 \mu \mathrm{l}$ of aCSF. Rats were then
Table 1. Treatments applied to the various experimental groups

\begin{tabular}{lccc}
\hline \hline \multicolumn{1}{c}{ Compound } & $\begin{array}{c}\text { No. of } \\
\text { Rats }\end{array}$ & Route & \multicolumn{1}{c}{ Dose } \\
\hline OT & 7 & ICV & $(0.3,3,30,300) \mathrm{ng}$ \\
{$\left[\mathrm{Thr}^{4}, \mathrm{Gly}^{7}\right]-$ OT } & 7 & ICV & $(0.3,3,30,300) \mathrm{ng}$ \\
AVP & 7 & ICV & $(0.3,3,30,300) \mathrm{ng}$ \\
Atosiban + OT & 7 & ICV & $300 \mathrm{ng}$ \\
Atosiban + OT & 7 & ICV & $(0.3,3,30,300) \mathrm{ng}$ \\
& & IV & $40 \mu \mathrm{g} / \mathrm{kg}$ \\
Hexamethonium + OT & 7 & ICV & $(0.3,3,30,300) \mathrm{ng}$ \\
Atropine + OT & 5 & IV & $20 \mathrm{mg} / \mathrm{kg}$ \\
& 5 & ICV & $(0.3,3,30,300) \mathrm{ng}$ \\
L-NAME + OT & 5 & ICV & $(0.3,3,30,300) \mathrm{ng}$ \\
& & IV & $30 \mathrm{mg} / \mathrm{kg}$ \\
\hline
\end{tabular}

Oxytocin (OT), $\left[\mathrm{Thr}^{4}, \mathrm{Gly}^{7}\right] \mathrm{OT}$, arginine vasopressin (AVP), atosiban, hexamethonium, atropine, and $N^{\omega}$-nitro-L-arginine methyl ester (L-NAME) were administered either intracerebroventricularly (ICV) in the left lateral ventricle or intravenously (IV) in the jugular vein to anesthetized female rats at the estrus stage.

killed with an overdose of pentobarbital sodium (180 mg/kg ip) and perfused with saline through the left cardiac ventricle. The brain was rapidly removed and sectioned in the coronal plane. Only females that displayed a blue labeling of the ventricles (i.e., with a correct implantation of the cannula) were included in the results.

Drug injections. Stock solutions $(10 \mu \mathrm{g} / \mathrm{ml})$ of OT, $\left[\mathrm{Thr}^{4}, \mathrm{Gly}^{7}\right] \mathrm{OT}$, and AVP (Sigma, Saint-Quentin Fallavier, France) in aCSF were prepared and stored at $-70^{\circ} \mathrm{C}$. The final solutions $(0.3,3,30$, and 300 ng in $10 \mu \mathrm{l}$ ) were freshly prepared on the day of the experiment and kept in ice until used. Atosiban (Ferring, Malmö, Sweden) was dissolved in aCSF for ICV injection (300 ng in $10 \mu \mathrm{l}$ ) or in $\mathrm{NaCl} 0.9 \%$ for intravenous injection $(40 \mu \mathrm{g} / \mathrm{kg})$. Hexamethonium, atropine and L-NAME (all from Sigma) were injected intravenously at doses of 20, 0.5 , and $30 \mathrm{mg} / \mathrm{kg}$, respectively.

Data analysis. Uterine activity was characterized by contractions separated by periods of silence. A contraction was defined as a transient IUP rise, the amplitude of which was greater than $1 \mathrm{mmHg}$, and that corresponded to a clearly identifiable peak on the recording trace. The frequency of IUP rises (number/min), their amplitude (increase above the basal level expressed in $\mathrm{mmHg}$ ), and their duration (s) were calculated. The effects of OT, $\left[\mathrm{Thr}^{4}, \mathrm{Gly}^{7}\right] \mathrm{OT}$, and AVP on IUP rises were assessed, taking the pressure level after the initial injection of aCSF as a control value. The effects of the tested drugs on IUP rises were searched for with the use of one-way ANOVA with repeated measures in case of a normal distribution of the data or otherwise with a $\chi^{2}$ test. We performed post hoc analysis using either the Holm-Sidak method following ANOVA or the Dunn's test following the $\chi^{2}$ test.

The effects of increasing doses of OT in the presence of a single dose of either atosiban or hexamethonium or atropine or L-NAME were expressed as percent changes compared with the IUP measured after aCSF injection. We performed comparisons using one-way ANOVA with repeated measures in case of a normal distribution of the data or using a $\chi^{2}$ test otherwise. We then performed comparisons with the control value using either the Holm-Sidak method following ANOVA or the Dunn's test following $\chi^{2}$ test. Statistical significance was at $P<0.05$. We used two-way ANOVA to search for possible drug effects.

\section{RESULTS}

OT and OT agonists. The effects of ICV OT on IUP rises are illustrated in Fig. 1, which shows that the frequency of uterine contractions increased with increasing doses of OT. This result 
Fig. 1. Example of intrauterine pressure (IUP) changes recorded in an anesthetized female rat at the estrus stage. Abscissa: time in seconds; ordinate: pressure expressed in $\mathrm{mmHg}$. Paired vertical bars indicate the intracerebroventricular (icv) administration of artificial cerebrospinal fluid (aCSF) (just before 1,000 s), followed by $0.3 \mathrm{ng}(2,000 \mathrm{~s}), 3$ (3,000 s), $30(4,000 \mathrm{~s})$, and $300 \mathrm{ng}(5,000 \mathrm{~s})$ of oxytocin (OT).

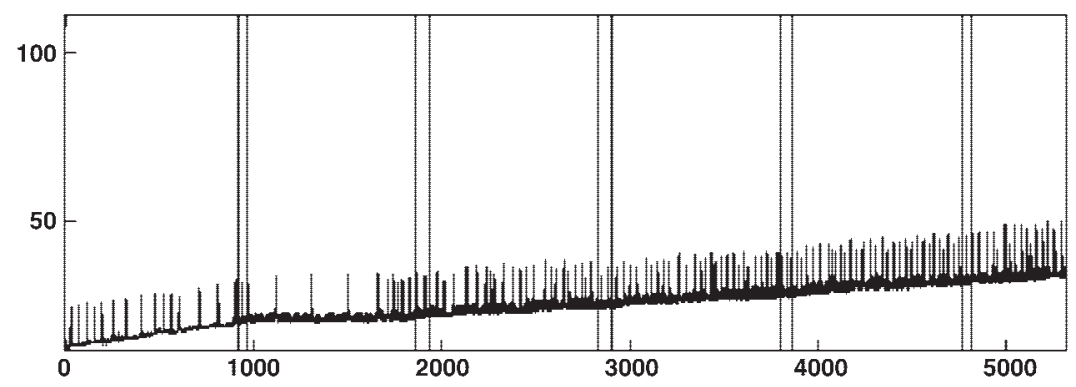

is summarized in the histograms of Fig. 2. OT increased the frequency of IUP rises in a dose-dependent manner $[F(4,24)=$ $6.351, P=0.001]$. Significant increases were observed with the doses of 3, 30, and $300 \mathrm{ng}$ OT (Fig. 2, top; $P=0.03, P=$ 0.003 , and $P<0.001$, respectively). OT significantly affected the amplitude of IUP rises $[F(4,24)=4.584, P=0.007]$, but only at the highest dose (Fig. 2, middle; $P=0.0012$ ), and did not affect rise duration (Fig. 2 , bottom) $[F(4,24)=1.211, P=$ 0.332]. The OT agonist $\left[\mathrm{Thr}^{4}, \mathrm{Gly}^{7}\right] \mathrm{OT}$ significantly increased the amplitude of IUP rises $\left(\chi^{2}=19.130, \mathrm{df}=4, P<0.001\right)$ at the doses of 3, 30, and $300 \mathrm{ng}$ (Fig. 2, middle; $P<0.05$ for each) but had no effect on their frequency (Fig. 2, top) $[F(4,24)=1.233, P=0.323]$. The duration of IUP rises was only affected at the dose of $0.3 \mathrm{ng}$ (Fig. 2, bottom, $\chi^{2}=10.949$, $\mathrm{df}=4, P=0.027)$. AVP did not affect either the frequency (Fig. 2, top, $\chi^{2}=4.971, \mathrm{df}=4, P=0.290$ ), amplitude (Fig. 2 , middle) $[\mathrm{F}(4,24)=2.386, P=0.079]$, or duration of IUP rises (Fig. 2, bottom, $\chi^{2}=6.324$, $\mathrm{df}=4, P=0.176$ ).

Comparisons of the effects of OT, $\left[\mathrm{Thr}^{4}, \mathrm{Gly}^{7}\right] \mathrm{OT}$, and AVP on IUP rises were performed with two-way ANOVA. The effects of these drugs on the frequency of IUP rises were significantly different $[F(2,90)=17.312, P<0.001]$, with both $\left[\mathrm{Thr}^{4}, \mathrm{Gly}^{7}\right] \mathrm{OT}$ and AVP differing from OT $(P<0.001$ in both cases). Also significant was a drug effect on the amplitude of IUP rises $[F(2,90)=13.166, P<0.001]$. $\left[\mathrm{Thr}^{4}, \mathrm{Gly}^{7}\right] \mathrm{OT}$ differed from OT $(P<0.001)$, whereas AVP did not $(P=$ $0.247)$. Finally, no drug effect was detected on the duration of IUP rises $[F(2,90)=2.509, P=0.087]$.

OT antagonist. When atosiban was injected ICV before OT administration, the dose-dependent effect of OT on the frequency of IUP rises disappeared (Fig. 3, top) $[F(4,16)=2.272$, $P=0.107]$, the amplitude of IUP rises diminished $[F(4,16)=$ 5.098, $P=0.008]$ at the three highest doses (Fig. 3, middle) $(P=0.023, P=0.017$, and $P=0.001$, for 3,30 , and $300 \mathrm{ng}$, respectively), and a moderate decrease of their duration was recorded $[F(4,16)=4.084, P=0.018]$, which reached statistical significance at the highest dose only (Fig. 3, bottom, $P=$ $0.006)$. When injected intravenously, atosiban also antagonized the effects of OT on the frequency (Fig. 3, top) $[F(4,16)=$ $1.695, P=0.200]$ and on the amplitude of IUP rises (Fig. 3, middle $)[F(4,16)=1.879, P=0.163]$.

Antagonists of autonomic efferent pathways. Hexamethonium (administered intravenously) antagonized the effects of OT on both the frequency (Fig. 4, top, $\chi^{2}=4.896$, $\mathrm{df}=4, P=$ 0.298 ) and the amplitude of IUP rises (Fig. 4 , middle, $\chi^{2}=$ 8.343 , $\mathrm{df}=4, P=0.08$ ). No effect on the duration of IUP rises was observed (Fig. 4, bottom).

Atropine (administered intravenously) abolished the effects of OT on the frequency of IUP rises (Fig. 4 , top) $[F(4,16)=$
2.335, $P=0.100]$ but did not do so on amplitude (Fig. 4, middle $)[F(4,16)=7.856, P=0.001]$. Indeed, with atropine, 30- and 300-ng doses of OT significantly increased the amplitude of IUP rises (Fig. 4, middle, $P=0.0002$ and $P=0.0105$, respectively). No effect was observed on the duration of IUP rises.

L-NAME (administered intravenously) antagonized the effects of OT on the frequency (Fig. 4, top) $[F(4,16)=1.262$, $P=0.325]$ and on the amplitude of IUP rises (Fig. 4, middle, $\left.\chi^{2}=1.958, \mathrm{df}=4, P=0.743\right)$. L-NAME had no effect on the duration of IUP rises.

\section{DISCUSSION}

In line with our previous study (8) demonstrating the involvement of a spinal neural control of uterine motility, the aim of the present study was to search for an involvement of supraspinal structures in this control and, if present, to determined the routes through which this control could be exerted. We used ICV OT to activate supraspinal nuclei in anesthetized female rats at the estrus stage. It has been shown that ICV doses of OT in the range of 5-90 ng ( $\sim 5-90 \mathrm{pmol})$ are efficient to induce erections in the male rat (2) and that ICV doses of $400 \mathrm{ng}(\sim 400 \mathrm{pmol})$ induce maternal behavior in virgin female rats (37) as well as induce their sexual receptivity (7). Similar doses, delivered by the intrathecal route, elicit penile erections in male rats $(0.3-300 \mathrm{ng} ; \sim 0.3-300 \mathrm{pmol})$ (19) and bladder contractions in conscious female rats $(30-100 \mathrm{ng} ; \sim 30-100$ pmol) (31) and modulate uterine activity in anesthetized female rats $(0.3-300 \mathrm{ng} ; \sim 0.3-300 \mathrm{pmol})(8)$. The doses used in the present study comply with these experimental protocols. We were aware that these doses, although commonly used in all pharmacological experiments performed in the rat, are largely above $\left(3 \times 10^{4}\right.$ times) the endogenous concentrations measured in CSF (41). Concerning other compounds (i.e., the OT agonist $\left[\mathrm{Thr}^{4}, \mathrm{Gly}{ }^{7}\right] \mathrm{OT}$ and the partial agonist AVP), we have used the same doses for the sake of comparison. Because their molecular weights are close to that of OT $\left(\left[\mathrm{Thr}^{4}, \mathrm{Gly}^{7}\right] \mathrm{OT}=\right.$ 940.1 and AVP $=1084.2)$, the injected doses are also close in terms of moles.

In this report, we show that, among the three parameters of uterine contractions, OT increased the frequency in the 3- to 300-ng dose range, whereas $\left[\mathrm{Thr}^{4}, \mathrm{Gly}^{7}\right] \mathrm{OT}$ increased the amplitude in the same dose range. $\left[\mathrm{Thr}^{4}, \mathrm{Gly}^{7}\right] \mathrm{OT}$ and OT itself display very similar affinities $\left(K_{\mathrm{d}}=\sim 2 \mathrm{nM}\right)$ for the OT receptor (15). However, although OT also binds AVP receptors $(5,39)$ with an affinity of $\sim 60 \mathrm{nM}(3,4),\left[\mathrm{Thr}^{4}, \mathrm{Gly}^{7}\right] \mathrm{OT}$ either does not (27) or has a very low affinity $(\sim 4 \mu \mathrm{M})(24)$. It is difficult to attribute the effects of OT on the frequency of 

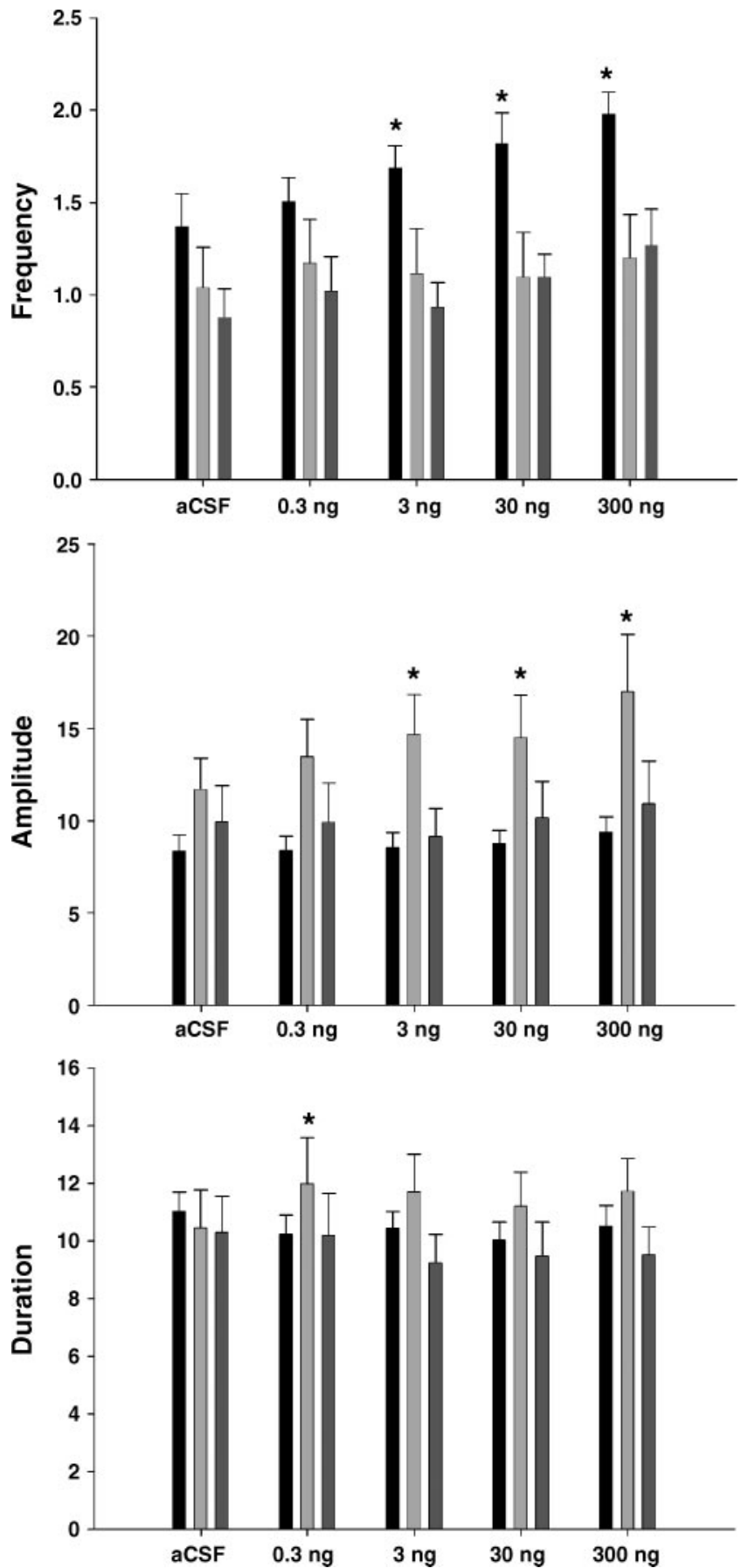

Fig. 2. Effects of OT and its agonists $\left[\mathrm{Thr}^{4}, \mathrm{Gly}^{7}\right] \mathrm{OT}$ and arginine vasopressin, administered icv, on IUP rises in anesthetized female rats. Histograms display the frequency (top, in number of IUP rises/min), amplitude (middle, in $\mathrm{mmHg}$ ), and duration (bottom, in seconds) of IUP rises after administration of aCSF followed by either OT $\left(0.3-300 \mathrm{ng}\right.$, black bars), $\left[\mathrm{Thr}^{4}, \mathrm{Gly}^{7}\right] \mathrm{OT}(0.3-300 \mathrm{ng}$, light gray bars), or arginine vasopressin (0.3-300 ng, dark gray bars). Results are expressed as means \pm SE of 7 rats/group. *Significantly different from corresponding aCSF value. See text for statistical significance.

uterine contractions to the activation of AVP receptors, since AVP itself had no effect on either the frequency or the amplitude of uterine contractions, although the affinity of AVP for the OT receptor is in the nanomolar range (3). Another explanation for the discrepancy between OT and its agonist relies on the possible existence of different OT receptor subtypes. Such a possibility has been suggested $(1,11,12)$, although only one type has been found so far $(5,18)$. Thus no clear-cut explanation for the discrepancy between the effects of
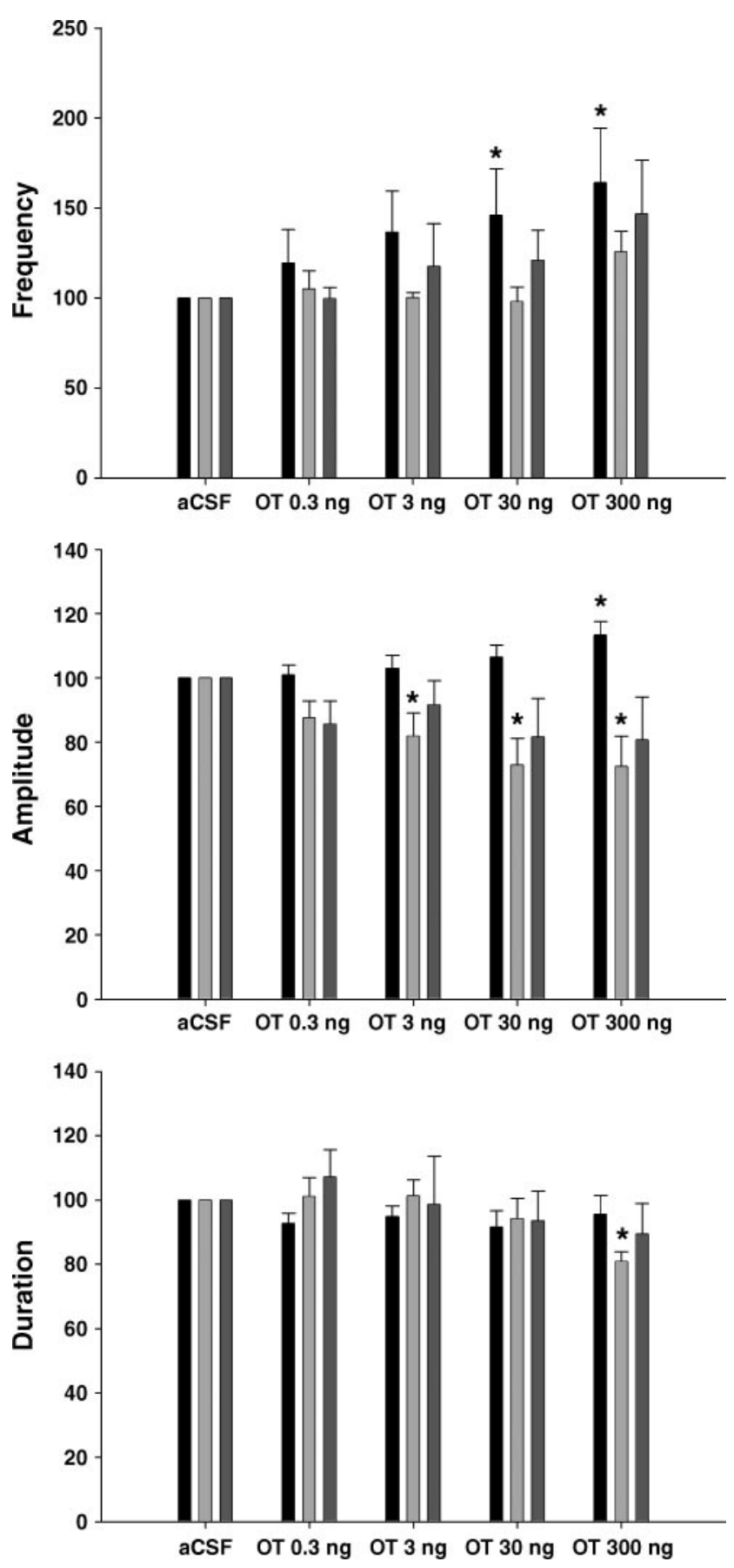

Fig. 3. Antagonism of OT-induced increase of IUP rises by atosiban. Histograms display the percent variation of the frequency (top), amplitude (middle), and duration (bottom) of IUP rises in anesthetized female rats. All rats received aCSF followed by OT (0.3-300 ng). One group (black bars) did not receive another treatment. The 2 other groups received, before aCSF, either an icv injection of 300 ng atosiban (light gray bars) or an intravenous injection of $40 \mu \mathrm{g} / \mathrm{kg}$ atosiban (dark gray bars). Results are expressed as percent change with respect to the value measured in the presence of aCSF alone. Note that the results shown for OT alone (black bars) are those of Fig. 2 converted to percent change. *Significantly different from corresponding aCSF value. See text for statistical significance. 
OT and its agonist on uterine motility can be put forward. It is noteworthy that this discrepancy has been observed in other experimental situations. OT, administered intrathecally at the lumbosacral spinal cord level, affects both the frequency and
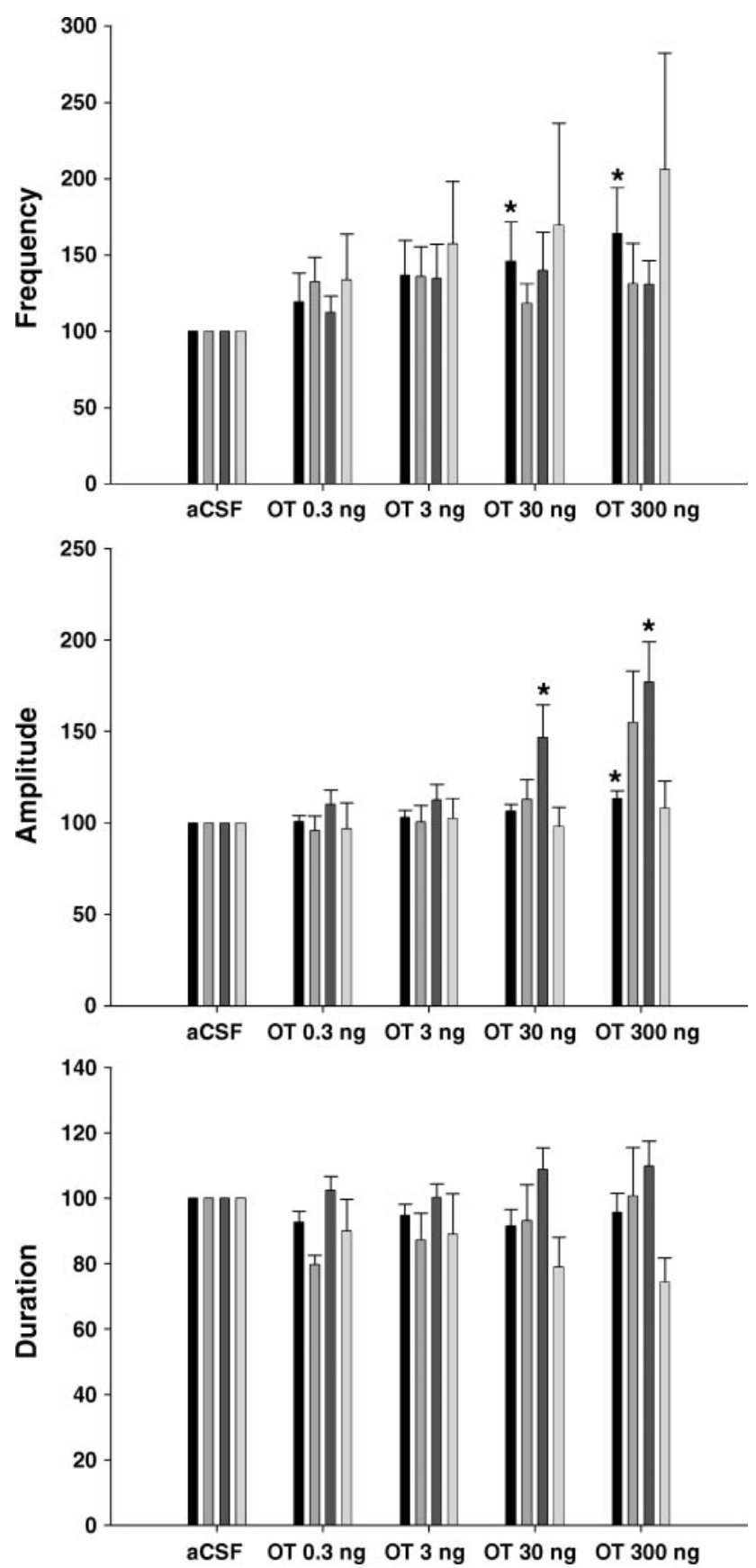

Fig. 4. Effects of OT, hexamethonium, atropine, and $N^{\omega}$-nitro-L-arginine methyl ester (L-NAME) on IUP rises in anesthetized female rats. Histograms display the percent variation of the frequency (top), amplitude (middle), and duration (bottom) of IUP rises in anesthetized female rats. All rats received aCSF followed by OT (0.3-300 ng). One group (black bars, left-most column) did not receive another treatment. The 3 other groups received, before aCSF, an intravenous injection of either $20 \mathrm{mg} / \mathrm{kg}$ hexamethonium (center left, gray bars), $0.5 \mathrm{mg} / \mathrm{kg}$ atropine (center right, dark gray bars), or $30 \mathrm{mg} / \mathrm{kg}$ L-NAME (right-most light gray bars). Results are expressed in percent change with respect to the value measured in the presence of aCSF alone. Note that the results shown for OT alone (black bars) are those of Fig. 2 converted to percent change. *Significantly different from corresponding aCSF value. See text for statistical significance. the amplitude of uterine contractions, whereas $\left[\mathrm{Thr}^{4}, \mathrm{Gly}^{7}\right] \mathrm{OT}$ only affects their amplitude (8). In male rats, intrathecal injections of OT significantly increase the frequency of erections and moderately affects their amplitude, whereas the reverse is true for $\left[\mathrm{Thr}^{4}, \mathrm{Gly}^{7}\right] \mathrm{OT}$ (19). Finally, although no simple explanation for the different effects of OT and its agonist on uterine motility can be provided, we have to emphasize that this observation seems to be a constant in different models.

The supraspinal control of uterine motility may rely on neuroendocrine and/or neural routes. The antagonism of the effect of ICV OT by intravenous atosiban suggests that at least part of this effect of OT is linked to the activation of peripheral OT receptors. This activation could be due to injected OT leaking into the bloodstream and reaching the uterus. This possibility is, however, unlikely because the leakage of OT into the bloodstream after its central injection can be considered negligible (51). More probable is the synthesis of OT and its release into the bloodstream after ICV injection of OT. Indeed, the application of OT onto hypothalamic brain slices facilitates the release of OT by magnocellular neurons (28).

Besides the neuroendocrine route, a neural control of uterine motility is also triggered by ICV application of OT. Indeed, the cholinergic nicotinic receptor antagonist hexamethonium, which blocks all synapses between pre- and postganglionic neurons, inhibited the OT-induced stimulation of IUP rises. This means that ICV OT also exerts its action through the activation of autonomic efferent pathways innervating the uterus. These pathways include sympathetic noradrenergic and parasympathetic cholinergic ones (50), the latter being, in the female rat, the dominant motor innervation of the uterus (21, $22,42,43,48)$. We therefore checked for a possible recruitment of this pathway by OT ICV using intravenously administered atropine, a cholinergic muscarinic antagonist. Atropine blocked the effects of OT on the frequency of uterine contractions, adding support to our hypothesis that ICV OT controls uterine motility through the activation of neural pathways. In the presence of atropine, ICV OT increased the amplitude of uterine contractions, whereas, in its absence, OT had no effect. A possible explanation is that atropine, injected intravenously, blocks the cholinergic input on the uterus and thus contractile noradrenergic sympathetic tone can no longer be antagonized (25). Another explanation is that atropine blocks the acetylcholine-induced synthesis of endothelial NO (14), which has a relaxant effect on the uterus. NO is also a classical transmitter of postganglionic parasympathetic fibers innervating the uterus (32), largely accepted as a relaxant neurotransmitter (29). Nevertheless, uterine effects of NO are complex: they have relaxant effects through the increased production of cGMP (16) and have a contractile effect through the production of prostaglandins (16). The blockade of the effects of ICV OT by the NO synthase inhibitor L-NAME suggests that the central administration of OT activates uterine motility at least in part through the activation of prostaglandin synthesis. It should be mentioned that L-NAME, at $30 \mathrm{mg} / \mathrm{kg}$, elicits a strong hypertensive response, which in turn induces a multitude of neurohormonal responses that may affect the uterus.

The existence of an OT-ergic paraventriculospinal pathway projecting to the parasympathetic nucleus has been demonstrated in the female rat (38). In a previous work (8), we have shown that OT, applied at the site of termination of this 
pathway, modulates uterine activity. Here, we show that such is also the case when OT is applied at its origin. The most plausible explanation for the present results is that the ICV application of OT activates this paraventriculospinal pathway. A direct demonstration of this hypothesis is still lacking, in particular because of the technical impossibility to selectively recruit the OT-ergic parvocellular neurons at the origin of the paraventriculospinal pathway and also of the difficulty of delivering at the same time OT ICV and OT antagonists intrathecally. Nevertheless, this hypothesis is in agreement with the observation that OT excites the paraventricular OTergic neurons of the hypothalamus both in vivo (17) and in brain slice preparations $(23,39)$ and stimulates a positive feedback mechanism of OT release by these neurons (28). If indeed the motility of the uterus is controlled by neuroendocrine and neural mechanisms, their respective roles and potencies remain to be explored in physiological conditions.

\section{ACKNOWLEDGMENTS}

The authors gratefully acknowledge the valuable help of Dr. Claude Barberis at INSERM, Montpellier, France, on OT antagonists, of Dr. Gilles Le Pape and Dr. Caroline Vieuille (Tours University) on statistical analysis, and of Blandine Barbier and Manuel Costa for taking care of the animals.

\section{GRANTS}

This work was supported by an institutional grant from Institut National de la Recherche Agronomique and by National Institutes of Health Grant 5R01 MH-059811-03.

\section{REFERENCES}

1. Anouar A, Clerget MS, Durroux T, Barberis C, and Germain G. Comparison of vasopressin and oxytocin receptors in the rat uterus and vascular tissue. Eur J Pharmacol 308: 87-96, 1996.

2. Argiolas A, Melis MR, and Gessa GL. Intraventricular oxytocin induces yawning and penile erection in rats. Eur J Pharmacol 117: 395-396, 1985.

3. Audigier $\mathbf{S}$ and Barberis C. Pharmacological characterization of two specific binding sites for neurohypophyseal hormones in hippocampal synaptic plasma membranes of the rat. EMBO J 4: 1407-1412, 1985.

4. Barberis C. $\left[{ }^{3} \mathrm{H}\right]$ vasopressin binding to rat hippocampal synaptic plasma membrane. Kinetic and pharmacological characterization. FEBS Lett 162: 400-405, 1983.

5. Barberis $\mathbf{C}$ and Tribollet E. Vasopressin and oxytocin receptors in the central nervous system. Crit Rev Neurobiol 10: 119-154, 1996.

6. Beach FA. Sexual attractivity, proceptivity, and receptivity in female mammals. Horm Behav 7: 105-138, 1976.

7. Benelli A, Poggioli R, Luppi P, Ruini L, Bertolini A, and Arletti R. Oxytocin enhances, and oxytocin antagonism decreases, sexual receptivity in intact female rats. Neuropeptides 27: 245-250, 1994

8. Benoussaidh A, Maurin Y, and Rampin O. Spinal effects of oxytocin on uterine motility in anesthetized rats. Am J Physiol Regul Integr Comp Physiol 287: R446-R453, 2004.

9. Berkley KJ, Hubscher $\mathbf{C H}$, and Wall PD. Neuronal responses to stimulation of the cervix, uterus, colon, and skin in the rat spinal cord. J Neurophysiol 69: 545-556, 1993.

10. Buijs RM. Intra- and extrahypothalamic vasopressin and oxytocin pathways in the rat. Pathways to the limbic system, medulla oblongata and spinal cord. Cell Tissue Res 192: 423-435, 1978.

11. Chan WY, Chen DL, and Manning M. Oxytocin receptor subtypes in the pregnant rat myometrium and decidua: pharmacological differentiations. Endocrinology 132: 1381-1386, 1993.

12. Chen DL, Chan WY, and Manning M. Agonist and antagonist specificities of decidual prostaglandin-releasing oxytocin receptors and myometrial uterotonic oxytocin receptors in pregnant rats. J Reprod Fertil 102: 337-343, 1994.

13. Collins JJ, Lin CE, Berthoud HR, and Papka RE. Vagal afferents from the uterus and cervix provide direct connections to the brainstem. Cell Tissue Res 295: 43-54, 1999.
14. Dalle Lucca JJ, Adeagbo AS, and Alsip NL. Oestrous cycle and pregnancy alter the reactivity of the rat uterine vasculature. Hum Reprod 15: 2496-2503, 2000.

15. Elands J, Barberis C, and Jard S. $\left[{ }^{3} \mathrm{H}\right]-\left[\mathrm{Thr}^{4}, \mathrm{Gly}^{7}\right] \mathrm{OT}$ : a highly selective ligand for central and peripheral OT receptors. Am J Physiol Endocrinol Metab 254: E31-E38, 1988.

16. Franchi AM, Chaud M, Rettori V, Suburo A, McCann SM, and Gimeno M. Role of nitric oxide in eicosanoid synthesis and uterine motility in estrogen-treated rat uteri. Proc Natl Acad Sci USA 91: 539543, 1994.

17. Freund-Mercier MJ and Richard P. Electrophysiological evidence for facilitatory control of oxytocin neurones by oxytocin during suckling in the rat. $J$ Physiol 352: 447-466, 1984.

18. Gimpl G and Fahrenholz F. The oxytocin receptor system: structure, function, and regulation. Physiol Rev 81: 629-683, 2001.

19. Giuliano F, Bernabe J, McKenna K, Longueville F, and Rampin O. Spinal proerectile effect of oxytocin in anesthetized rats. Am J Physiol Regul Integr Comp Physiol 280: R1870-R1877, 2001.

20. Harper MJK. Gamete and zygote transport. In: The Physiology of Reproduction, edited by Knobil E and Neill JD. New York: Raven, 1994, p. $123-187$.

21. Hollingsworth $\mathbf{M}$. The innervation of the rat cervix and its pharmacology in vitro and in vivo. Br J Pharmacol 52: 539-547, 1974.

22. Hollingsworth M. Mechanical responses of rat isolated uterine horns to transmural stimulation. Br J Pharmacol 55: 41-46, 1975.

23. Inenaga $\mathbf{K}$ and Yamashita $\mathbf{H}$. Excitation of neurones in the rat paraventricular nucleus in vitro by vasopressin and oxytocin. $J$ Physiol 370: 165-180, 1986.

24. Kiraly M, Audigier S, Tribollet E, Barberis C, Dolivo M, and Dreifuss JJ. Biochemical and electrophysiological evidence of functional vasopressin receptors in the rat superior cervical ganglion. Proc Natl Acad Sci USA 83: 5335-5339, 1986.

25. Loffelholz K and Muscholl E. A muscarinic inhibition of the noradrenaline release evoked by postganglionic sympathetic nerve stimulation. Naunyn Schmiedebergs Arch Pharmacol 265: 1-15, 1969.

26. Long JA and Evans HM. The oestrus cycle in the rat and associated phenomena. Mem Univ Cal 6: 1-148, 1922.

27. Lowbridge J, Manning M, Haldar J, and Sawyer WH. Synthesis and some pharmacological properties of [4-threonine,7-glycine]oxytocin, [1-(L-2-hydroxy-3-mercaptopropanoic acid), 4-threonine, 7-glycine]oxytocin (hydroxy[ $\left.\mathrm{Thr}^{4}, \mathrm{Gly}^{7}\right]$ oxytocin), and [7-Glycine]oxytocin, peptides with high oxytocic-antidiuretic selectivity. J Med Chem 20: 120-123, 1977.

28. Moos F, Freund-Mercier MJ, Guerne Y, Guerne JM, Stoeckel ME, and Richard P. Release of oxytocin and vasopressin by magnocellular nuclei in vitro: specific facilitatory effect of oxytocin on its own release. $J$ Endocrinol 102: 63-72, 1984.

29. Norman J. Nitric oxide and the myometrium. Pharmacol Ther 70: 91-100, 1996

30. Ortega-Villalobos M, Garcia-Bazan M, Solano-Flores LP, NinomiyaAlarcon JG, Guevara-Guzman R, and Wayner MJ. Vagus nerve afferent and efferent innervation of the rat uterus: an electrophysiological and HRP study. Brain Res Bull 25: 365-371, 1990.

31. Pandita RK, Nylen A, and Andersson KE. Oxytocin-induced stimulation and inhibition of bladder activity in normal, conscious rats-influence of nitric oxide synthase inhibition. Neuroscience 85: 1113-1119, 1998.

32. Papka RE, McNeill DL, Thompson D, and Schmidt HH. Nitric oxide nerves in the uterus are parasympathetic, sensory, and contain neuropeptides. Cell Tissue Res 279: 339-349, 1995.

33. Papka RE and Traurig HH. Autonomic efferent and visceral sensory innervation of the female reproductive system: special reference to neurochemical markers in nerves and ganglionic connections. In: Nervous Control of the Urogenital System, edited by Maggi CA. Chur, Switzerland: Harwood Academic, 1993, p. 423-466.

34. Papka RE, Traurig HH, Schemann M, Collins J, Copelin T, and Wilson K. Cholinergic neurons of the pelvic autonomic ganglia and uterus of the female rat: distribution of axons and presence of muscarinic receptors. Cell Tissue Res 296: 293-305, 1999.

35. Papka RE, Williams S, Miller KE, Copelin T, and Puri P. CNS location of uterine-related neurons revealed by trans-synaptic tracing with pseudorabies virus and their relation to estrogen receptor-immunoreactive neurons. Neuroscience 84: 935-952, 1998. 
36. Paxinos G and Watson C. The Rat Brain in Stereotaxic Coordinates. New York: Academic, 1998.

37. Pedersen CA and Prange AJ Jr. Induction of maternal behavior in virgin rats after intracerebroventricular administration of oxytocin. Proc Natl Acad Sci USA 76: 6661-6665, 1979.

38. Puder BA and Papka RE. Hypothalamic paraventricular axons projecting to the female rat lumbosacral spinal cord contain oxytocin immunoreactivity. J Neurosci Res 64: 53-60, 2001.

39. Raggenbass M. Vasopressin- and oxytocin-induced activity in the central nervous system: electrophysiological studies using in-vitro systems. Prog Neurobiol 64: 307-326, 2001.

40. Russell JA, Leng G, and Douglas AJ. The magnocellular oxytocin system, the fount of maternity: adaptations in pregnancy. Front Neuroendocrinol 24: 27-61, 2003.

41. Sansone GR, Gerdes CA, Steinman JL, Winslow JT, Ottenweller JE, Komisaruk BR, and Insel TR. Vaginocervical stimulation releases oxytocin within the spinal cord in rats. Neuroendocrinology 75: 306-315, 2002.

42. Sato S, Hayashi RH, and Garfield RE. Mechanical responses of the rat uterus, cervix, and bladder to stimulation of hypogastric and pelvic nerves in vivo. Biol Reprod 40: 209-219, 1989.

43. Sato Y, Hotta H, Nakayama H, and Suzuki H. Sympathetic and parasympathetic regulation of the uterine blood flow and contraction in the rat. J Auton Nerv Syst 59: 151-158, 1996.
44. Silverman AJ and Zimmerman EA. Magnocellular neurosecretory system. Аnпи Rev Neurosci 6: 357-380, 1983.

45. Soloff MS, Schroeder BT, Chakraborty J, and Pearlmutter AF. Characterization of oxytocin receptors in the uterus and mammary gland. Fed Proc 36: 1861-1866, 1977

46. Soloff MS and Swartz TL. Characterization of a proposed oxytocin receptor in the uterus of the rat and sow. J Biol Chem 249: 1376-1381, 1974.

47. Soloff MS, Swartz TL, and Steinberg AH. Oxytocin receptors in human uterus. J Clin Endocrinol Metab 38: 1052-1056, 1974.

48. Stjernquist $\mathbf{M}$ and Owman C. Cholinergic and adrenergic neural control of smooth muscle function in the non-pregnant rat uterine cervix. Acta Physiol Scand 124: 429-436, 1985.

49. Swanson LW and McKellar S. The distribution of oxytocin- and neurophysin-stained fibers in the spinal cord of the rat and monkey. J Comp Neurol 188: 87-106, 1979.

50. Traurig HH and Papka RE. Autonomic efferent and visceral sensory innervation of the female reproductive system: special reference to the functional roles of nerves in reproductive organs. In: Nervous Control of Urogenital System, edited by Maggi CA. Chur, Switzerland: Harwood Academic, 1993, p. 103-141.

51. Yashpal K, Gauthier S, and Henry JL. Oxytocin administered intrathecally preferentially increases heart rate rather than arterial pressure in the rat. J Auton Nerv Syst 20: 167-178, 1987.

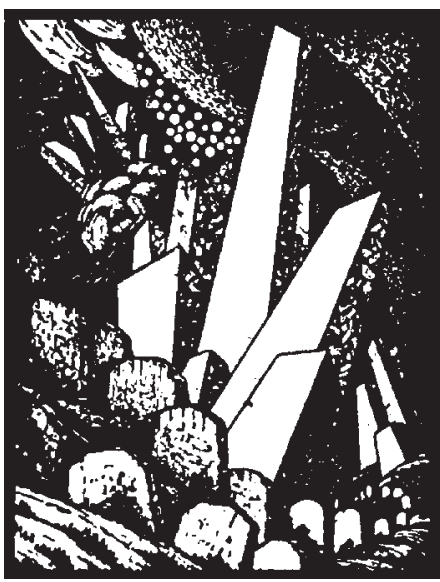

